\title{
PNC e Redes Sociais: um estudo em torno de desafios e oportunidades na web social
}

\author{
João Pinto \\ Centro de Investigação em Artes e Comunicação (CIAC), Universidade do Algarve, Portugal \\ Laboratório de Educação a Distância e Elearning (LE@D), Universidade Aberta, Portugal \\ Teresa Cardoso \\ Universidade Aberta, Laboratório de Educação a Distância e Elearning (LE@D), Portugal \\ Ana Isabel Soares \\ Centro de Investigação em Artes e Comunicação (CIAC), Universidade do Algarve, Portugal
}

\begin{abstract}
In this text we propose to reflect about the relationship between the Portuguese National Film Plan and Social Networks, in the context of current society, in a network, presenting, for this purpose, the ongoing research project "Education, Film, Social Networks: a study about the National Film Plan." The fundamentals of the study include the concepts of open education and audiovisuals, envisaged under the theoretical triad Education / Film / Social Networks, with the purpose of understanding how this Portuguese Plan makes use of digital social networks online, the maximum exponent of the tools associated to the social web. For this purpose, the relationship between film, education and social networks is considered in particular, taking into account the digital lifestyles of contemporary society and the importance of developing and disseminating different literacies. Such reflections will also take into account the practice of the National Film Plan, an initiative of the Portuguese government created to promote the development of film literacy in the school environment. Finally, it will be possible to conclude that the affinity between film and education goes back to the origins of film itself, having evolved not only with filmic technologies and pedagogical methodologies, but also with the influence of new lifestyles in society. Thus, in nowaday's digital, online and audiovisual society, and since the relationship between cinema and education is dynamic too, it now finds both other challenges and new opportunities.
\end{abstract}

Keywords: Education, Film, Social Networks, Portuguese National Film Plan, filmic Literacies.

\section{Introdução}

De acordo com o entendimento de Castells (2011), a revolução tecnológica fez emergir nos dias de hoje uma sociedade em rede, na qual as pessoas se veem como cidadãos ativos, construtores da inteligência coletiva, e não apenas enquanto consumidores passivos de uma cultura criada pelos outros. As redes sociais tornaram- se os novos meios de difusão, com possibilidades inovadoras de interações (Pinto 2017) e o surgimento de novos dispositivos de comunicação no nosso quotidiano tem vindo a revolucionar a forma como vivenciamos o audiovisual (Reia-Baptista 2006). Este, por seu lado, tem tido no cinema, desde o surgimento desta arte na última década do século XIX, um dos mais completos modos de expressão cultural da sociedade industrial e tecnológica contemporânea, que moldaram de maneira definitiva o modo de ver e de vivenciar, nomeadamente, as imagens.

No contexto do que se entende por educação formal, informal ou não formal, a relação entre cinema e educação integra a história do cinema desde o seu início: para lá do intuito de entretenimento que tinham, enquanto curioso evento de feira que começaram por ser os objetos cinematográficos foram desde logo percebidos, de maneira mais ou menos explícita, como meios de propagação educativa. Porém, e num quase paradoxo simultâneo, segundo Duarte (2002), mesmo quando a Sétima Arte se afirma como fonte fértil de conhecimentos, nem sempre é entendida deste modo, principalmente por parte das entidades e instituições educativas. Ora, continuando a assumir tal papel educacional na sociedade, o cinema encontra hoje novas possibilidades e caminhos para intervir no panorama educativo da sociedade, e conta com públicos participativos, que, além de inertes $e$ quotidianos consumidores, podem ser produtores de conteúdos audiovisuais (Oliveira e Caetano 2017, 55). Neste sentido, e no desenho da moldura teórica enquadradora da nossa reflexão, começamos por considerar o cinema não apenas como uma forma de expressão que integra a lista das várias artes - e que Canudo $(1924,3)$ considera como a "sétima arte" -, nem só enquanto "produto de entretenimento" (Toldo e Lopes 2017, 172), mas, sobretudo, como "agente de apoio à aprendizagem" (Linhares e Ávila 2017, 99). No contexto tecnológico da "sociedade em rede" (Castells 2011), passaremos ainda por uma reflexão acerca do cinema e da educação perante as dinâmicas criadas pela Internet - mais especificamente, teremos em conta o fenómeno das redes sociais, da "cibercultura" (Lévy 1999, 17) e da web social (O'Reilly 2011, 1). 
Finalmente, apresentamos os fundamentos metodológicos do estudo "Educação, Cinema e Redes Sociais: uma investigação sobre o Plano Nacional de Cinema," projeto de investigação acolhido pelo Centro de Investigação em Artes e Comunicação (CIAC) da Universidade do Algarve, desenvolvido com apoio da Fundação para a Ciência e a Tecnologia (SFRH/BD/137359/2018) e integrado no doutoramento em Média-Arte Digital do primeiro autor, sob supervisão científica das coautoras do texto.

Neste projeto de investigação, o objeto de estudo é, então, o Plano Nacional de Cinema (PNC), e assumemse como objetivos principais: compreender de que modo esta iniciativa governamental tem recorrido às redes sociais digitais online; sistematizar boas práticas; e contribuir para a definição de um conjunto de recomendações para potenciar 0 recurso às ferramentas utilizadas. No âmbito dos novos paradigmas da ciência aberta, acreditamos, assim, contribuir para o conhecimento científico nas áreas da Educação, do Cinema e das Redes Sociais. Recordese, antes de prosseguir, que o PNC, criado em 2013 por iniciativa governamental conjunta da Presidência do Conselho de Ministros, através do Secretário de Estado da Cultura e do Ministério da Educação e Ciência, tem como objetivos, entre outros, "a promoção da literacia para o cinema" e "a divulgação de obras cinematográficas nacionais" (idem) junto do público escolar, garantindo aos alunos das escolas abrangidas pelo programa os instrumentos essenciais de leitura e interpretação de tais obras.

\section{Contextualização teórica}

\section{O cinema, arte e educação}

Poucos anos depois de ter surgido, o cinema veio a ser entendido como manifestação artística e os seus criadores preocuparam-se em que essa afirmação se fosse consolidado a cada nova obra produzida. Em 1911, Ricciotto Canudo realizou uma série de palestras, mais tarde publicadas sob o título Manifeste des Sept Arts (Canudo 1923, 3), nas quais defendeu o cinema como "sétima arte (...) conferindo-lhe um caráter estético" e reconhecendo "o cinema enquanto linguagem, capaz de renovar, transformar e difundir as outras Artes, num projeto de Arte Total" (Brandão 2008, 7). Nas palavras daquele autor:

Mas esta arte de síntese total que é o Cinema, este fabuloso recém-nascido da Máquina e do Sentimento, começa a cessar os seus vagidos, entra na sua infância. Em breve virá a adolescência agarrar-Ihe a inteligência e multiplicar-Ihe os sonhos. Exigimos que se the precipite o desenvolvimento, que se acelere o advento da sua juventude. Necessitamos do Cinema para criar a arte total para a qual desde sempre tenderam todas as demais artes. (Canudo 1991)

No início, a exibição dos filmes era a demonstração de uma novidade; a partir da afirmação do cinema enquanto arte, a sua quase natural evolução foi no sentido artístico que extravasava o propósito de entreter e se voltava, também, para um entendimento de si mesmo. As histórias contadas em cada filme passavam a ter construções narrativas com enredos, personagens e outros elementos, incipientes nalgumas das primeiras experiências, e cada vez mais complexas, que iam além do sentido estético que uma atenção meta-artística, ou autotélica, necessariamente comporta.

A Primeira Guerra Mundial (1914-1918), cujos campos de batalha se situavam primordialmente na Europa, fez deslocar a produção de filmes do Velho Continente para os Estados Unidos, mais precisamente para o Sul da Costa Oeste. Hollywood, complexo de estúdios na cidade de Los Angeles, transformou-se então no centro da indústria cinematográfica, e o cinema viria a funcionar em grande medida como produto de puro entretenimento e alienação de massas, numa lógica comercial e de retorno financeiro. Para Toldo e Lopes (2017), tal ideologia industrial parecia não ter "preocupações com a inovação estética" (ibid, 172), nem com as opções dos autores, e privilegiava antes as preocupações comerciais dos produtores. Por seu lado, a Nouvelle Vague, movimento artístico do cinema francês, que se desenrolou principalmente durante a década de 1960, defendeu "a autoria do diretor na obra cinematográfica e [trouxe] ao cinema, temáticas jovens, heróis antiéticos e rompimentos com a linguagem clássica" (Toldo e Lopes 2017, 173). Essas ideias acabariam por influenciar o cinema industrial produzido por Hollywood, inspirando autores e diretores, entre outros, com "novas temáticas e novas proposições estéticas aos filmes" (ibid, 190). No entanto, estes autores recordam que a ambivalência do cinema de arte ou de indústria-lazer/entretenimento é uma questão tão antiga quanto o próprio cinema, algo que se reflete na forma como é visto inclusivamente pelos agentes da educação.

Ora, como se começou por afirmar, a associação entre o cinema e a educação remonta ao início da história cinematográfica (Pinto, Cardoso e Soares, 2019, 5). Os produtores e os diretores de cinema consideraram o cinema, desde logo, como uma poderosa ferramenta para a formação, educação e reflexão do indivíduo na sociedade humana. Ao analisarem a relação entre cinema e educação, Linhares e Ávila (2017) sublinham que aquele sempre foi "considerado como um instrumento de lazer aliado ao mercado capitalista com o intuito de manipulação da sociedade", mas que, por outro lado, foi tido como "agente de apoio à aprendizagem" (ibid, 99). Os autores concluem que esta dicotomia contribuiu para algum afastamento entre o 
cinema e a educação, assim como para a não valorização do potencial do cinema nas aprendizagens, uma vez que as obras da Sétima Arte foram mais frequentemente associadas a produtos de lazer e entretenimento - 0 que lhe retirava alguma credibilidade, nomeadamente para o senso comum.

Tendo em consideração a diversidade de saberes integrados num filme, somos levados a concluir que a sua exibição é muito mais do que um processo de estímulos audiovisuais ou uma ilustração da realidade. A utilização do cinema na área da educação é, pois, "um meio de ensino-aprendizagem" (Pinto, Cardoso e Soares, 2019, 5), que permite lançar luz sobre aspetos sociais, culturais, históricos, literários e políticos. Num contexto de sala de aula, o recurso ao visionamento de obras cinematográficas é visto por Silva (2007) como elemento fundamental para romper barreiras entre 0 quotidiano da escola e o da vida fora dela, bem como para diminuir separações metodológicas entre 0 pensar, o sentir e o aprender, ampliando a possibilidade de escuta e de reflexão do aluno. Trevizan e Crepaldi (2009), citados por Alves da Silva (2014), mencionam que "a linguagem audiovisual é bastante atraente e pode produzir experiências diferenciadas e enriquecedoras na sala de aula" (Trevizan e Crepaldi 2009, 363). Portanto, conclui este autor, "os filmes podem ser utilizados como 'porta de acesso' a informações geradoras de conhecimento, que não se esgotam em si mesmas" (ibid, 369). Ou seja, através da análise fílmica pode ser ativado um amplo processo de perceção e reflexão sobre os saberes e as práticas inerentes à linguagem cinematográfica, possibilitando a realização de aprendizagens que conduzam à construção de conhecimento. Tendemos a concordar com Linhares e Ávila (2017), nomeadamente quando afirmam que "as aproximações do cinema e da educação são múltiplas e complexas, extrapolando a simples associação do filme ao conteúdo" (ibid, 89). É nesse sentido que a seguir exploramos tais aproximações, adensando a equação quando as observamos à luz de convergências suscitadas pelo (novo) mundo digital.

\section{O paradigma de uma web social}

Numa sociedade tecnológica como a atual, altamente mediatizada, os conteúdos audiovisuais têm conquistado particular destaque nas redes sociais, entre as quais emerge um crescente interesse em "contar histórias com imagens, sons e movimentos" (Fantin 2007, 1). Tal interesse leva-nos a considerar uma das principais características do cinema, o seu potencial enquanto arte narrativa por excelência. Esta realidade de confluência de dois media - as redes sociais e o cinema -, a que os alunos tendem a estar permanentemente expostos e com os quais estão cada vez mais interligados, tem, de igual forma, implicações no modo como se concretizam aprendizagens, quer em contextos formais e/ou escolarizados, quer em contextos informais ou não formais. A educação deverá, assim, "considerar novos rumos, estratégias e metodologias, para que possa responder às necessidades dos indivíduos e instituições" (Pinto 2017, 8).

A revolução tecnológica digital fez emergir um novo paradigma social, descrito por Castells (2011) como "sociedade em rede." Nesta, as pessoas interagem quotidianamente com os mais variados conteúdos digitais, numa espécie de "tsunami mediático" (Trültzsch-Wijnen 2019, 61), com "impactos no estilo de vida e no comportamento dos indivíduos na sociedade, bem como na forma de aprenderem" (Pinto e Cardoso $2017,79)$. Tal confere novos significados aos conceitos de tempo e de espaço, e transforma de maneira profunda os processos de comunicação e de perceção da realidade, num "presente amplo" (Gumbrecht 2014, 87), alargado pelas experiências de simultaneidade comunicativa.

Ao mesmo tempo que alteram toda a dinâmica de recurso e exposição dos indivíduos aos media, estas transformações conferem aos utilizadores um conjunto de capacidades e verdadeiro poder. Isto é, em vez de mero consumidor de conteúdos, cada indivíduo desta sociedade mediatizada torna-se igualmente potencial e quantas vezes real - produtor desses mesmos conteúdos. Bruns (2006) cunhou o termo "produsers" para se referir a estes novos cidadãos do mundo (digital) em rede. Trata-se de um conceito que emerge de fenómenos como a cibercultura e a cultura participatória, e que tem implicações transversais às várias dimensões da vida dos indivíduos.

Para melhor compreender tais transformações, reportamo-nos às contribuições de Pierre Lévy (1999), quando define a cibercultura como um "conjunto de práticas, de atitudes, de modos de pensamento e de valores que se desenvolvem juntamente com o crescimento do ciberespaço" (Lévy 1999, 17), e de Rheingold (2012), que identifica a "emergência de uma cultura participativa [na qual] as pessoas que acham que são capazes de criar e também de consumir são cidadãos diferentes. E as suas participações tornam a sociedade diferente e melhor" (Rheingold 2012, 249). Um cenário assim desenhado confere à relação entre cinema e educação novos sentidos e desafios, dado o "enorme potencial de compartilhamento de conhecimento" (Santos 2012, 83); ratifica-se desta forma a cultura da participação, pois estimula-se a conectividade, a interatividade e a cooperação através da Internet, com reflexos nas formas de aprender.

De facto, as evoluções tecnológicas, nomeadamente nos meios digitais baseados na Internet, transformaram de modo radical a "produção, difusão e consumo de obras audiovisuais, até mesmo a obra cinematográfica" 
(Barone 2009, 45). Os espaços web, com especial destaque para as redes sociais online, são hoje porventura os meios mais utilizados para a construção e a disseminação de conteúdos artísticos e culturais, entre os quais se incluem os audiovisuais. Assim se democratiza o acesso à participação dos indivíduos, os produsers, cada vez mais libertos de constrangimentos físicos, técnicos e geográficos.

As novas formas de distribuir, consumir e interagir com conteúdos estão diretamente relacionadas com a evolução tecnológica da própria Internet desde a Web 1.0 à atual Web 3.0, pelo que importa percorrer, sumariamente, a evolução deste meio. As primeiras páginas de Internet caracterizavam-se por ser websites estáticos, através dos quais se disponibilizavam conteúdos sem qualquer possibilidade de interação com os utilizadores. Estávamos na década de 1990 e o máximo que se podia fazer, além de visualizar os conteúdos, era selecionar hiperligações que, acionadas com um clique do botão do rato, fazia abrir outras páginas e, quando muito, permitia descarregar conteúdos. Esta fase da Internet viria a ser conhecida como a Web 1.0 - a sua primeira geração, caracterizada por apenas permitir utilizações do tipo "read-only" (Gil 2014, 1). Ainda assim, pode dizer-se que já se estava perante "uma verdadeira Sociedade da Informação" (idem), pelo facto de os utilizadores terem ao dispor uma "grande biblioteca digital, permitindo o acesso a uma grande quantidade de conteúdo" (Santarosa, Debora e Schneider 2014, 2), disponível a qualquer altura e em qualquer local. Os motores de pesquisa, como o Google, são o melhor exemplo deste tipo de serviços oferecidos nesta geração, por permitirem procurar informações na Internet de forma fácil e rápida.

No início do presente século, surge a Web 2.0. A designação desta segunda geração nomeava um tipo de páginas de Internet que estimulavam os utilizadores a darem opiniões, partilharem conteúdos e até mesmo a construírem espaços online nos quais disponibilizassem conteúdos criados por si, como os blogues, designação que, lembramos, deriva da redução do termo inglês weblog, que designa uma espécie de diário (log) disponibilizado na rede (web). Nestes diários na rede, os participantes podem interagir (através da publicação de comentários a publicações, por exemplo), sugerir, criticar, contrapor ideias e adicionar conteúdos. A esta interação mais alargada chamou Rheingold (2012) uma "arquitetura de participação" (Rheingold 2012, 2), ou "web Social", como havia denominado O'Reilly $(2011,1)$, uma expressão que sublinha a participação do utilizador como consumidor, produtor e distribuidor de conteúdos. Num tal contexto de partilha, discussão e reflexão crítica, estão criadas as "condições para se poder afirmar que se promove a passagem de uma Sociedade da Informação para a Sociedade do Conhecimento" (Gil 2014 , 2). São exemplos paradigmáticos da Web 2.0 os já referidos blogues (em que utilizadores sem conhecimentos de programação web podem criar espaços online com os mais variados tipos de conteúdos) e as redes sociais digitais, que viriam a potenciar possibilidades de interação nunca antes disponibilizadas. De um "utilizador passivo" (Santos e Petersen 2014, 66), na Web 1.0, passamos a encontrar outro, "menos utilitarista e mais interativo, participativo, colaborativo" (Santos e Petersen 2014, 66).

Com a utilização em larga escala da Internet começaram a colocar-se questões de gestão de informação (como organizar, de forma simples e eficiente, as enormes quantidades de conteúdos arquivados na Internet), mas também de disponibilização (como garantir a facilidade de pesquisa e acesso, conforme as necessidades específicas de cada utilizador) - questões relacionadas com o conceito de "Big Data," tal como o descreve, entre outros, Tomás $(2013,24)$. Das respostas a estas preocupações veio a surgir a Web 3.0 - a terceira geração, também conhecida como web semântica. O conceito de "Web semântica" (Berners-Lee, Hendler e Lassila 2001) caracteriza a capacidade de os sistemas informáticos interpretarem o conteúdo disponível nos websites e conseguirem entender de forma diferenciada 0 significado das palavras. Ou seja, os conteúdos são interpretados de acordo com os contextos em que surgem, tendo em conta as características de cada utilizador e o seu perfil, e procura-se apresentar a cada utilizador exatamente aquilo que pretende, com base no que os sistemas informáticos conseguem reunir a partir do seu comportamento online. Existe, portanto, uma "personalização da navegação na web, com programas que percebem especificidades e preferências" (Santarosa, Debora e Schneider 2014, 2). Este facto altera de maneira profunda a nossa experiência na Internet, pois "os mecanismos de inteligência artificial imbuídos de semântica são capazes de introduzir dimensões diversas, tanto no âmbito pessoal como no social" (Tomás 2013, 152) e "promovem, cada vez mais, a personalização em contexto aberto (social) da aprendizagem" (Tomás 2013, 152).

A utilização crescente de dispositivos móveis, como os Smartphones, por seu lado, veio permitir a experiência da Internet móvel, cujo acesso é garantido sem constrangimentos de local, tempo ou dispositivo. Isto tem alterado a natureza da rede, na qual o utilizador tende a passar cada vez mais tempo ligado, num estado de disponibilidade permanente, "em comunicação constante com aqueles com quem mantém relações, com as redes sociais de que participa, usando a conectividade recentemente adquirida para informar seus pares ou seus amigos sobre o que se passa com ele e no seu entorno (...). Em outras palavras, desde 
então que estimula a troca e a criação de conteúdos integrados e de interesse comum" (Santos e Petersen 2014, 86).

A evolução da Internet revela, assim, uma mudança de utilização, que "passa de uma ênfase prioritariamente instrumental para uma amplamente relacional" (Santos e Petersen 2014, 64). De início, o uso era fundamentalmente instrumental, isto é, a Internet era usada principalmente como instrumento para atividades de pesquisa, recolha e publicação de informação, mas, acima de tudo, como meio de consumo de conteúdos. Atualmente, 0 foco dos utilizadores centra-se na participação coletiva e na colaboração interativa, de tal forma que as características de uma web instrumental perdem importância em benefício dos de uma web social, fortalecida pelas interações e vínculos sociais, isto é, de modo a tornar "possíveis novas formas de sociabilidade" (Rheingold 2012, 192).

Recentrando-nos no cinema, entendemos que os estilos de vida digital tornam os indivíduos consumidores de cinema de outros e noutros espaços ou por outros meios (Internet, smartphones, etc.), com os quais interagem de modo que até há pouco tempo era dificilmente concebível, senão mesmo impensável. Quando Moreira (2017) recorda que o PNC pretende criar um "novo tipo de espectador que não frequente unicamente as salas comerciais" (Moreira 2017, 4), também reconhece o facto de, atualmente, se viver cada vez mais afastado da forma tradicional de ver filmes. A autora lembra que existe um público vasto, composto pelas novas gerações, que se habituou a aceder a conteúdos audiovisuais de formas inovadoras e distintas das tradicionais - e que é necessário trazêlas para o entendimento do cinema.

\section{Contextualização metodológica}

\section{Fundamentos e procedimentos}

Pelo exposto nos parágrafos anteriores, justifica-se um estudo sobre o modo como o PNC recorre às redes sociais para cumprir parte relevante do seu papel pedagógico e discutir criticamente novas abordagens e campos de trabalho, face às constantes evoluções da nossa sociedade. Foi esta problemática que permitiu corporizar os objetivos do projeto de investigação referido, o qual se encontra alicerçado em diversos fundamentos metodológicos. Desses, destacam-se o estudo de caso e a análise da literatura publicada. $O$ estudo de caso tem por objeto o PNC, e, como finalidade, perceber de que modo e com que resultados esta iniciativa faz uso das redes sociais - e, nesse processo, em que medida as redes sociais dão forma e consistência àquele propósito, nas suas vertentes concretas e nos seus aspetos conceptuais. Para tal, recorreremos a diversos instrumentos de recolha e análise de dados - entre outros: entrevistas, observação de interações online e análise das estatísticas disponibilizadas pelas bases de dados das redes sociais. Quanto à revisão da literatura, de natureza qualitativa e caráter interpretativo, procederse-á à análise de conteúdo orientada pela matriz analítico-metodológica e conceptual do MAECC $\circledast$, Meta-modelo de Análise e Exploração do Conhecimento Científico® (Cardoso, Alarcão e Celorico 2010 2013).

O desenvolvimento da investigação compreende três etapas distintas, mas complementares, que a seguir se apresentam de modo breve. A etapa 1 é preparatória. Nela pretendemos consolidar a contextualização das temáticas em análise e complementar a moldura teórica do estudo; destina-se, esta etapa inicial, a preparar ferramentas e estratégias para a implementação do trabalho. Assim, assume particular importância a análise documental, por permitir contextualizar o PNC, a nível macro, por exemplo, enquadrando-o nacionalmente, considerando o programa JuventudeCinema-Escola (aplicado na região do Algarve, que serviu de modelo ao PNC), e ainda o Plano Nacional de Leitura (PNL), visto que esta última iniciativa (instituída em 2006 por Resolução do Conselho de Ministros), igualmente governamental e complementar do currículo escolar, comunga de muitos dos objetivos e estratégias do PNC. Outro procedimento nuclear nesta fase é o aprofundamento da análise dos objetivos da Agenda $2030^{1}$ das Nações Unidas para o Desenvolvimento Sustentável. Pretendemos, com essa análise, garantir que a nossa investigação cumpre desígnios integrados nesta Agenda. Neste contexto, sublinhamos 0 enquadramento da nossa investigação nas estratégias para o acesso a uma educação inclusiva e a promoção das oportunidades de aprendizagens ao longo da vida (objetivo 4), preocupação presente, desde o início, na missão do PNC e um propósito patente no documento governamental "Grandes Opções do Plano para 2016$19^{\prime 2}$, por sua vez alinhado com os programas Portugal $2020^{3}$ e Estratégia Europa 2020.

A etapa 2 é composta pela consolidação de várias tarefas encetadas na etapa anterior, como a consolidação da Revisão da Literatura, que inclui um Mapeamento das publicações significativas e mais recentes, assim como a aplicação dos instrumentos de recolha de dados, através da Observação de Casos e de Inquéritos por Questionário e Entrevista a alguns agentes do PNC. O referido Mapeamento permitirá sistematizar o conhecimento produzido e publicado sobre a problemática em estudo, apresentando-se os pressupostos teóricos da investigação, resultante da Análise Documental de publicações, sobretudo disponibilizadas online, estas pesquisadas na web, principalmente nos repositórios institucionais das instituições de ensino superior, no RCAAP Repositórios Científicos de Acesso Aberto de Portugal, 
na b-on - Biblioteca do Conhecimento Online, e no Google Académico.

Assim, retomaremos a Revisão da Literatura, direcionada agora para uma contextualização mesomicro do PNC, sendo o mapeamento aprofundado com uma análise de conteúdo orientada, como mencionado, pela matriz analítico-metodológica e conceptual do MAECC®, Meta-modelo de Análise e Exploração do Conhecimento Científico $\AA$ (Cardoso, Alarcão e Celorico 2010 2013). Este modelo investigativo, de lógica descritivo-interpretativa, permitirá avançar com um estado da arte e assegurar a resposta a algumas questões de investigação: Quem desenvolve investigação nesta área? Quais os temas e os termos específicos nela veiculados? Que referenciais e metodologias a enquadram? Que conclusões são avançadas? Que propostas de estudos futuros são sugeridas?

Quanto aos inquéritos, serão aplicados a amostras representativas dos intervenientes no PNC, incluindo elementos do seu público-alvo. Assumirão abordagens metodológicas qualitativas e quantitativas, numa combinação útil pela possibilidade de recolha de diferentes tipos de dados, com perguntas fechadas (que devolvem dados de natureza quantitativa) e perguntas abertas (em que se recolhem dados de natureza qualitativa).

Quanto à Observação de Casos, é um procedimento que visa o estudo dos comportamentos, através de grelhas de observação, que os envolvidos no PNC apresentam em determinadas situações. Especificamos a observação das dinâmicas criadas pelo PNC nas redes sociais, nomeadamente no perfil respetivo no Facebook, assim como as respetivas interações, em termos qualitativos e quantitativos.

A etapa 3 destina-se às grandes tarefas de análise e discussão dos dados obtidos na etapa anterior. Inclui um balanço crítico dos resultados, bem como a apresentação de casos de boas práticas, recomendações e medidas de ação passíveis de serem tomadas pelos intervenientes no PNC. No final, decorrendo da experiência adquirida, pretende-se disseminar os resultados obtidos, incentivando às boas práticas identificadas no PNC, sempre privilegiando a disponibilização livre do conhecimento, através do acesso aberto e da ciência aberta.

No que concerne à organização institucional da investigação, assumimos um alinhamento com as políticas, nacionais e europeias, que incentivem parcerias e sinergias entre instituições de ensino superior e unidades de I\&D. Assim, estão envolvidas a Universidade Aberta (UAb), única universidade pública portuguesa dedicada exclusivamente ao ensino a distância, e a Universidade do Algarve (UAlg), com reconhecidos créditos nas áreas dos estudos do audiovisual. Estão também envolvidas duas unidades de I\&D, a UID4372, Laboratório de Educação a Distância e Elearning (LE@D) da UAb, dedicado à investigação fundamental e aplicada em Educação Aberta e a Distância e em Elearning na Sociedade em Rede, e a UID4019, Centro de Investigação em Artes e Comunicação (CIAC) da UAlg, dedicado à investigação nas áreas das novas literacias dos media e das artes.

\section{Análise preliminar exploratória}

Numa investigação que se propõe estudar a utilização das redes sociais, assume particular importância a observação deste uso. Tal implica o recurso a um modelo de recolha de dados que permita uma posterior análise de dados, tanto a nível quantitativo como qualitativo.

Uma das metodologias mais seguidas para analisar conteúdos e interações nas Redes Sociais é o recurso a tipos específicos de software que fazem uma análise quantitativa de forma automática. Para estudar esta possibilidade, começamos por fazer uma incursão na literatura científica relacionada com o tema, seguida de uma exploração da tecnologia em causa.

Assim, observamos que o bom funcionamento deste software está dependente do acesso que as redes sociais lhes permitem, algo que tem vindo a ser restringido por razões inerentes ao acesso aos dados dos utilizadores e à eventual quebra da privacidade. De facto, tem havido alterações legislativas recentes, não tendo ainda sido publicados estudos científicos que possam fundamentar qualquer decisão - o que torna a sua utilização arriscada. Embora redes como o Facebook e o Twitter disponibilizem aplicações próprias para análise dos conteúdos nelas publicados, não funcionam da mesma forma nem produzem o mesmo tipo de dados, algo que inviabilizava efetuar comparações entre os dados obtidos.

Detetamos ainda que nenhum destes tipos de software funciona com os grupos do Facebook, característica que deixa de fora o principal espaço de presença do PNC nas redes sociais. Mas, como nenhum deles abrange todas as redes sociais utilizadas pelo PNC, não é possível recolher dados uniformes e passíveis de serem comparados de modo científico, facto que inviabiliza esta opção.

Em suma, este tipo de software pode ser útil para a análise de conteúdos numa determinada rede social e, talvez, até seja mais indicado para a área de Marketing, mas não responde aos requisitos do nosso estudo. Como tal, fomos instigados a desenhar uma metodologia específica de recolha e análise de dados que pudesse ser implementada, tendo em conta as diferentes especificidades dos espaços do PNC nas redes sociais, materializada numa tabela de Excel construída especificamente para arquivo de dados, e que se assume como base de dados relacional. 
Para cada publicação, recolhemos o dia e a hora respetivos e registamos igualmente se se trata de conteúdo próprio ou de uma partilha de terceiros. Quanto às interações de que cada publicação foi alvo, recolhemos informações sobre as emoções, partilhas, comentários e respostas. Classificaremos ainda o tipo de conteúdos e faremos uma análise detalhada ao texto escrito nas publicações.

Dado que o trabalho de recolha de dados está em curso durante 0 ano de 2020, apresentamos alguns dados preliminares quanto às redes sociais utilizadas pelo PNC. Nas entrevistas exploratórias, identificou-se que o PNC utiliza o Facebook (tem uma página pública e um grupo aberto), o Instagram, o Twitter e o YouTube. A Tabela 1 mostra o ano de criação dos espaços do PNC em cada uma destas redes sociais. Verificamos que a página no Facebook é o espaço mais antigo (existe há sete anos), seguido pelo grupo no Facebook (com cinco). Em relação ao YouTube e ao Twitter, os perfis do PNC foram ali criados respetivamente em 2016 e 2017. Quanto ao perfil no Instagram, encontramos evidências de que foi criado em outubro de 2019, dado que a primeira publicação data de 31 de outubro deste ano: é a rede social utilizada pelo PNC há menos tempo.

\begin{tabular}{|l|l|}
\hline \multicolumn{1}{|c|}{ Rede Social } & Ano \\
\hline Facebook - Página & 2013 \\
\hline Facebook - Grupo & 2015 \\
\hline YouTube & 2016 \\
\hline Twitter & 2017 \\
\hline Instagram & 2019 \\
\hline
\end{tabular}

Tabela 1- Ano de criação do perfil do PNC em diferentes redes sociais. Fonte: os autores.

A Tabela 2 mostra a quantificação do público que o PNC tem em cada um dos espaços identificados. De referir que cada rede social utiliza designações diferentes para o seu público: seguidores, membros ou subscritores. Tendo o mês de janeiro de 2020 como marco referencial para o início desta recolha de dados, observámos que os espaços no Facebook são os que apresentam um maior público, sendo que a página tinha 2200 seguidores e o grupo 3800 membros. Os outros apresentavam muito menos público:198 seguidores no Twitter, apenas nove no Instagram e sete no YouTube.

\begin{tabular}{|l|l|}
\hline \multicolumn{1}{|c|}{ Rede Social } & \multicolumn{1}{c|}{ Público } \\
\hline Facebook - Página & 2200 seguidores \\
\hline Facebook - Grupo & 3800 membros \\
\hline
\end{tabular}

\begin{tabular}{|l|l|}
\hline Twitter & 198 seguidores \\
\hline Instagram & 9 seguidores \\
\hline YouTube & 7 subscritores \\
\hline
\end{tabular}

Tabela 2 - Tipo e quantidade de público nas diferentes redes sociais do PNC. Fonte: os autores.

Estes dados mostram que os espaços do PNC nas redes sociais fortemente conotadas com a imagem e 0 vídeo, como é o caso do Instagram e do YouTube, tinham um público muito reduzido, residual até. Numa primeira análise, notamos que ou foram criados recentemente (caso do Instagram) ou têm poucos conteúdos publicados (caso do YouTube), podendo ser espaços ainda em fase de experimentação, o que não Ihes confere ainda visibilidade significativa. Por outro lado, pode considerar-se que o público formalmente implicado ou envolvido, porque registado, é diminuto, embora possa haver um público mais amplo e alargado que tenha optado por não ser regular ou constante, mas pontual (donde a opção de não se registar como seguidor/subscritor). Neste caso, poderá dizer-se que estamos perante utilizadores (ou consumidores de conteúdos) passivos, que possamos comparar aos "lurkers". Embora a definição de lurker (alguém oculto que espreita) remonte aos primeiros fóruns online do fim do século passado, ganhou novas atualizações no contexto das atuais redes sociais e comunidades de aprendizagem online. Continua a identificar os utilizadores que frequentam esses espaços de forma discreta, que adotam uma atitude silenciosa, procurando não se comprometer com as dinâmicas de comunicação, não interagindo com os demais, nem fazendo publicações (Nonnecke e Preece 1999, 1). Esta classificação não deve ser entendida como pejorativa, uma vez que estes também são consumidores dos conteúdos; parece evocar quiçá uma postura online prudente e responsável.

Acreditamos que este tipo de utilizador também frequente os espaços do PNC nas redes sociais com mais público, como é o caso da página e do grupo no Facebook, que estão configurados como de acesso público. Significa isso que podem aceder aos conteúdos sem qualquer autorização nem verificação prévia. No entanto, esta perceção será depois confirmada (ou refutada) através de outros instrumentos de recolha de dados, a aplicar numa fase posterior do estudo. Destacamos o caso do grupo no Facebook, cuja privacidade está configurada como sendo do tipo "Público», o que significa que "qualquer pessoa pode ver quem faz parte do grupo e o que é publicado" (Coutinho 2014, 70). Esta opção não é muito comum nesta rede social, uma vez que, de uma forma geral, os administradores optam por uma privacidade do tipo «Fechado», "o que implica que as pessoas 
interessadas em visualizar os conteúdos do grupo têm que tornar-se membros dele" (Pinto 2017, 71). Entendemos que esta estratégia do PNC, de abrir ao público os seus espaços nas redes sociais, configura uma implementação das políticas de livre acesso aos conteúdos, uma iniciativa muito própria dos movimentos da Educação Aberta (Santos 2012, 72) e dos Recursos Educacionais Abertos (Paris OER Declaration 2012, 1), pelo que a consideramos uma boa prática.

Na Tabela 3, hierarquizam-se os espaços do PNC nas diversas redes sociais, tendo em conta a média de publicações no primeiro trimestre de 2020. Da sua análise, concluímos que as publicações se concentram quase totalmente no ambiente do Facebook, com o grupo a registar uma média de 60 publicações e a página 38. Consideramos que as reduzidas publicações registadas nas outras redes sociais estão em linha com os dados da Tabela 2 e parecem confirmar as conclusões enunciadas.

\begin{tabular}{|l|c|}
\hline \multicolumn{1}{|c|}{ Rede Social } & Publicações \\
\hline Facebook - Grupo & 60 \\
\hline Facebook - Página & 38 \\
\hline Twitter & 3 \\
\hline Instagram & 5 \\
\hline YouTube & 2 \\
\hline
\end{tabular}

Tabela 3 - Quantidade de publicações nas diferentes redes sociais do PNC. Fonte: os autores.

Sobre este dados preliminares, concluímos que parece existir uma aposta no trabalho com Facebook, que se pode explicar, por exemplo, por ser a rede social mais utilizada em Portugal, mais transversal a todos os tipos de públicos (Os Portugueses e as Redes Sociais 2017), e por permitir a utilização de diversos tipos de conteúdos (texto, imagem, vídeo). Ainda assim, o trabalho detetado noutras redes sociais, embora com menos público, pode ser um indicador do interesse em descobrir novas oportunidades, noutras redes sociais, procurando seguir as tendências de utilização por parte dos públicos abrangidos pelo PNC.

\section{Conclusão}

Ao longo deste texto, constatamos que a evolução tecnológica tem vindo a provocar transformações, nomeadamente sociais e educacionais, as quais, por sua vez, também têm vindo a suscitar transformações na produção, difusão e consumo do cinema.

Com o desenvolvimento do projeto de investigação apresentado, acreditamos ser possível determinar e sustentar uma visão sobre o PNC nos novos contextos das potencialidades advindas da web social, além de almejar a preparação do indivíduo para ser melhor consumidor/produtor/construtor dos seus próprios conteúdos audiovisuais, na perspetiva de uma cidadania mais plena. Esperamos, também, e como antes referido, contribuir para a consolidação e a disseminação do conhecimento e para o avanço da ciência e da tecnologia nas áreas da Educação, do Cinema e das Redes Sociais.

Finalmente, recordamos que a relação do cinema com a educação remonta às origens do próprio cinema, tendo evoluído com as metodologias pedagógicas e, sobretudo, com a adoção das tecnologias disponíveis. De facto, as novas tecnologias digitais têm vindo a provocar novos estilos de vida na sociedade, um cenário no qual o cinema encontra hoje novas possibilidades e caminhos de intervir, incluindo no panorama educativo, contando com públicos participativos, que, além de inertes e quotidianos consumidores, podem ser produtores ativos de conteúdos audiovisuais, nomeadamente em diferentes media e redes sociais.

\section{Notas finais \\ ${ }^{1}$ https://www.un.org/sustainabledevelopment \\ 2 https://dre.pt/application/file/a/74008569 \\ 3 www.portugal2020.pt/Portal2020 \\ 4 https://infoeuropa.eurocid.pt/registo/000044430}

\section{Bibliografia}

Alves da Silva, Josineide. 2014. Cinema e educação: o uso de filmes na escola / Movies and education: the use of films in school. In Revista Intersaberes, 361-373. www.uninter.com/ intersaberes/index.php/revista/article/viewFile/642/421.

Acedido a 2 de abril 2020.

Barone, João Guilerme. 2009. Cenários tecnológicos e institucionais do cinema brasileiro na década de 90. Porto Alegre, Brasil: Sulina.

Berners-Lee, Tim, Hendler, James, and Lassila, Ora. (2001). The Semantic Web. Scientific American. http://wwwsop.inria.fr/acacia/cours/essi2006/Scientific\%20American_\% 20Feature\%20Article_\%20The\%20Semantic\%20Web_\%20 May\%202001.pdf. Acedido 28 de março 2020.

Brandão, Helena S. M. 2008. A fábrica de imagens: o cinema como arte plástica e rítmica. Universidade de Lisboa. http://repositorio.ul.pt/bitstream/10451/341/1/19611_ulf10689 13_tm.pdf. Acedido a 20 de março 2020.

Bruns, Axel. 2006. Towards Produsage: Futures for User-Led Content Production. In Proceedings Cultural Attitudes towards Communication and Technology 2006, pages pp. 275-284, Tartu, Estonia. https://eprints.qut.edu.au/4863/1/4863_1.pdf. Acedido a 28 de fevereiro 2020.

Canudo, Ricciotto. 1924. La Gazette des Sept Arts. 2. Paris. In La Gazette des Sept Arts. 10. Paris. http://www.cineres sources.net/consultationPdf/web/o002/2687. pdf. Acedido a 9 de abril 2020.

Cardoso, Teresa, Alarcão, Isabel, and Celorico, Jacinto A. 2010. Revisão da Literatura e Sistematização do Conhecimento. Porto: Porto Editora. 
Cardoso, Teresa, Alarcão, Isabel, and Celorico, Jacinto A. 2010. "MAECC®: um caminho para mapear investigação". Indagatio Didactica, 5 (2), 289-299. CIDTFF - Centro de Investigação em Didáctica e Tecnologia na Formação de Formadores, Universidade de Aveiro. ISSN: 1647-3582. http://revistas.ua.pt/index.php/ID/article/view/2452/2323.

Acedido a 6 de abril 2020.

Castells, Manuel. 2011. A Sociedade em Rede. A Era da Informação: Economia, Sociedade e Cultura (4 ed., Vol. 1). Lisboa: Fundação Calouste Gulbenkian.

Coutinho, Virginia. 2014. The Social Book: Tudo o que precisa de saber sobre o Facebook. Conjuntura Actual.

Duarte, Rosália. 2002. Cinema \& educação: refletindo sobre cinema e educação. Belo Horizonte: Autêntica.

Fantin, Mônica. 2007. Média-Educação e Cinema na Escola. Teias, 14-15. https://www.e-publicacoes.uerj.br/index.php/rev istateias/article/view/24008/16978. Acedido a 26 de março 2020.

Gil, Henrique. 2014. A passagem da WEB 1.0 para a WEBb 2.0 e... WEB 3.0: potenciais consequências para uma «humanização» em contexto educativo. Educatic - Boletim informativo, 1-2. https://repositorio.ipcb.pt/handle/10400.11/ 2404. Acedido a 2 de abril 2020.

Gumbrecht, Hans U. 2014. Nosso Amplo Presente: O tempo e a cultura contemporânea. Trad.: Soares, A. I. São Paulo: UNESP, 2015. ISBN 978-85-393-0600-8.

Lévy, Pierre. 1999. Cibercultura. São Paulo: Editora 34.

Linhares, Nunes, and Ávila, Éverton. 2017. Cinema e educação para além do conteúdo. Revista Tempos e Espaços em Educação, 10(21), 89. https://doi.org/10.20952/revtee.v 10i21.6335. Acedido a 5 de abril 2020.

Moreira, Cláudia. 2017. Cinema chega às Escolas: a importância do Plano Nacional de Cinema, Covilhã: Universidade da Beira Interior, Faculdade de Artes e Letras. https://ubibliorum.ubi.pt/handle/10400.6/6706. Acedido a 9 de abril 2020.

Nonnecke, Blair. and Preece, Jennifer. 1999. Shedding light on Lurkers in Online Communities. In Ethnographic Studies in Real and Virtual Environments: Inhabited Information Spaces and Connected Communities. Organizador por K. Buckner, 123-128. Edinburgh. http://citeseerx.ist.psu.edu/viewdoc/ download?doi=10.1.1.94.4833\&rep=rep1\&type=pdf. Acedido a 11 de abril 2020.

Oliveira, Sandra, and Caetano, Rita. 2017. Literacia para os Média e Cidadania Global: Caixa de Ferramentas. Lisboa: CIDAC.

O'Reilly, T. 2005. "Web 2.0: Compact Definition?" in O'Reilly' Radar - Insight, Analysis, and Research About Emerging Technologies. http://radar.oreilly.com/2005/10/web-20-comp act-definition.html. Acedido a 6 de abril 2020.

Os Portugueses e as Redes Sociais. 2019. Marktest. https://www.marktest.com/wap/private/images/Logos/Folheto _Portugueses_Redes_Sociais_2019.pdf. Acedido a 2 de abril 2020.

Paris OER Declaration. 2012. World Open Educational Resources (OER) Congress Unesco. Paris. http://ww w.unesco.org/new/fileadmin/MULTIMEDIA/HQ/CI/WPFD200 9/English_Declaration.html. Acedido a 10 de fevereiro 2020. Pinto, João, and Cardoso, Teresa. 2017. Redes Sociais e Educação Aberta: Que Relação?. In Redes e Mídias Sociais (2 ${ }^{a}$ edição). Organizado por Patricia Torres. Brasil: Editora
Appris. http://hdl.handle.net/10400.2/7212. Acedido a 4 de abril 2020.

Pinto, João, Cardoso, Teresa, and Soares, Ana I. 2019. Cinema and Education: what relationship in the internet age? In Proceedings of Digicom 2019 - 3rd International Conference on Design and Digital Communication. Editado por Nuno Martins e Daniel Brandão. Barcelos: IPCA - Instituto Politécnico do Cávado e do Ave. ISBN 978-989-54489-5-1. https://digicom.ipca.pt/docs/DIGICOM2019-Proceedings.pdf. Acedido a 6 de abril 2020.

Pinto, João, Cardoso, Teresa, and Soares, Ana I. 2019a. Educação, Cinema e Redes Sociais: um olhar a partir do Plano Nacional de Cinema. Translocal - Culturas Contemporâneas Locais e Urbanas, no 4, ISSN 2184-1519. Universidade da Madeira. http://translocal.cm-funchal.pt/wpcontent/uploads/2019/01/EducacaoCinemaERedes-

Sociais_PNC.pdf. Acedido a 10 de abril 2020.

Pinto, João. 2017. Formação aberta e online, redes sociais e inclusão digital: o projeto Reviver na Rede. Lisboa: Universidade Aberta. http://hdl.handle.net/10400.2/6930. Acedido a 6 de abril 2020.

Reia-Baptista, Victor. 2006. New environments of media exposure. In Internet and narrative structures: From media education to media pedagogy and media literacy, Nordicom, Göteborg University. http://hdl.handle.net/10400.1/9125 Acedido a 6 de abril 2020.

Rheingold, Howard. 2012. Net Smart - How to Thrive Online. Cambridge, Massachusetts, EUA: MIT Press.

Santarosa, Lucilia M., Debora, Conforto, and Schneider, Fernanda C. 2014. Tecnologias na Web 2.0: o empodera mento na educação aberta. In Colóquio Luso-Brasileiro de Educação a Distância e Elearning. Lisboa. "Colóquio LusoBrasileiro...: atas". Lisboa: Universidade Aberta. LEAD. ISBN 978-972-674-738-3. 1-18. http://repositorioaberto.uab.pt/han dle/10400.2/3071. Acedido a 11 de abril 2020.

Santos, Andreia I. 2012. Educação Aberta: histórico, práticas e o contexto dos Recursos Educacionais Abertos. In Recursos Educacionais Abertos, práticas colaborativas e políticas públicas. Organizado por Bianca Santana, Carolina Rossini, Nelson De Luca Preto. São Paulo: UFBA. http://aber ta.org.br/livrorea/artigos/wp-content/uploads/2012/05/REAsantos.pdf. Acedido a 28 de março 2020.

Santos, Andreia Inamorato. 2012 Educação Aberta: histórico, práticas e o contexto dos Recursos Educacionais Abertos. In Recursos Educacionais Abertos práticas colaborativas e políticas públicas, (1a), 71-89. http://aberta.org.br/livr orea/artigos/wp-content/uploads/2012/05/REA-santos.pdf.

Acedido a 15 de abril 2020.

Santos, Francisco, and Petersen, Cristina. 2014. Redes sociais, redes de sociabilidade. In Revista Brasileira de Ciências Sociais, 63-78. http://dx.doi.org/10.1590/S010269092014000200005 . Acedido a 9 de abril 2020.

Silva, Roseli P. 2007. Cinema e Educação. São Paulo: editora Cortez.

Toldo, Giordano S., and Lopes, Fernando D. 2017. Cinema como arte ou entretenimento: uma visão de seus realizadores e a estrutura organizacional de suas produtoras. In REAd Revista Eletrônica de Administração, 23(2), 167-190. https://doi.org/10.1590/1413.2311.176.60848. Acedido a 9 de abril 2020.

Tomás, Cecília. 2013. Web semântica e personalização: repercussões da interação semântica com recursos 
educacionais abertos na identidade virtual do estudante e nos ambientes de aprendizagem online. Lisboa: Universidade Aberta. http://repositorioaberto.uab.pt/handle/10400.2/3309. Acedido a 6 de abril 2020.

Trültzsch-Wijnen, Christine W. 2019. Educação para os média como uma disciplina transversal. In Literacias cívicas e críticas: refletir e praticar (pp. 61-68). Organizado por M. J. Brites, I. Amaral, and M. T. da Silva. Áustria: Salzburg University of Education Stefan Zweig. www.lasics.uminho.pt/ojs/index.php/cecs_ebooks/article/view /3184/3078. Acedido a 6 de abril 2020. 